\title{
Factors Influencing College Students' Mental Health Promotion: The Mediating Effect of Online Mental Health Information Seeking
}

\author{
Wenen Chen ${ }^{1}$, Qian Zheng ${ }^{1,2, *}$, Changyong Liang ${ }^{1,3}$, Yuguang Xie ${ }^{1}$ and Dongxiao Gu ${ }^{1,3}$ \\ 1 The School of Management, Hefei University of Technology, Hefei 230009, China; xsccwe@hfut.edu.cn (W.C.); \\ cyliang@hfut.edu.cn (C.L.); 13095537911@163.com (Y.X.); gudongxiao@hfut.edu.cn (D.G.) \\ 2 The School of Management, Anhui Science and Technology University, Fengyang 233100, China \\ 3 Key Laboratory of Process Optimization and Intelligent Decision-making of Ministry of Education, \\ Hefei 230009, China \\ * Correspondence: zhengq@ahstu.edu.cn
}

Received: 23 May 2020; Accepted: 30 June 2020; Published: 3 July 2020

check for updates

\begin{abstract}
For college students, mental health is an important factor in ensuring their ability to study and have a normal life. This research focuses on factors affecting the mental health of college students in the information network society. We constructed a theoretical model that influences their online mental health information seeking behavior from internal and external perspectives, and by extension, affects their mental health. Through the data obtained by field research and questionnaire survey on the online mental health information seeking behavior of some college students in Internet health information platforms, a structural equation model is used to test the hypotheses. Results show that the quality of external Internet platforms and the quality of internal electronic health literacy have a significantly positive impact on the online health information searching behavior of college students; electronic health literacy and online mental health information seeking behavior have significantly direct positive effects on college students' mental health. Further, online health information searching behavior has a significant mediating effect between Internet platform quality, electronic health literacy, and college students' mental health. The research conclusions have theoretical value and practical significance to study the factors influencing college students' mental health in the context of information network society.
\end{abstract}

Keywords: college students' mental health; information network society; online health information searching; the external quality of Internet platforms; electronic health literacy

\section{Introduction}

College students are one of the backbone forces for the future development of society [1]. According to statistics, there are more than 40 million college students in China alone. For college students living far away from their families, mental health is one of the important factors in ensuring their ability to study and have a normal life. A survey of 2018 white papers on the mental health of China's urban residents concluded that $73.6 \%$ of college students were in a state of mental sub-health. The problems were most acute among those who were highly educated. The mental health problems of college students are mainly manifested in interpersonal communication disorders, Internet addiction, and emotional problems [2,3]. These mental health problems can lead to bad behaviors such as excessive drinking, illegal-drug use, skipping school, irritability, and even suicide, and can seriously affect college students' ability to study and their quality of life. One could argue that the state of college students' mental health is one of the most important issues that society should pay close attention to. 
College students are the "natives" of the information society, born and raised in the age of Internet information; the breadth, intensity, and duration of their online searching surpasses that of other groups [4], and the ability to perceive and use data is also higher than other groups [5]. Information about mental health is an important part of the material searched on the Internet [6]. With the help of Internet platforms, college students usually choose to search for information about mental health on relevant medical websites and app; or by communicating with online doctors to determine whether their mental state is at a healthy level. From the internal perspective of information search subjects, Canadian scholar C.D. Norman and others hold that the influencing factors of online information searching have a positive correlation with electronic health literacy at the perspective of individual ability [7]. According to Delone and McLean's successful model of information systems, people's online behavior is motivated mainly by the quality of external information [8]. The emergence of individual behavior is the result of the comprehensive effect of external environmental factors and internal subjective factors, so it is necessary to consider them together. In addition, the ultimate goal of college students' online health information searching is their mental health. Shaw and Gant think the Internet can positively promote the physical health of individuals [9]; Aref-Adib and other scholars believe that online mental health information seeking behavior (OMHISB) has a positive relationship with mental health [10]; Peris and others think that good online relationships with other people have a positive effect on mental health [11]. In this information network society, factors affecting the mental health of college students need to be further explored. Therefore, this study deals with college students' mental health, focusing on the following three issues:

1. What are the internal and external factors that influence college students' OMHISB?

2. What is the comprehensive effect of online health mental information seeking behavior and college students' electronic health literacy on mental health promotion?

3. What is the role of OMHISB in the relationship between internal and external factors and mental health promotion?

The remaining sections are arranged as follows: Section 2 introduces the main theoretical background and research hypotheses of the study; Section 3 makes an empirical analysis based on survey data; Section 4 expounds on the empirical analysis results; Section 5 discusses the theoretical and practical significance of the study; and Section 6 is the research conclusion.

\section{Theoretical Background and Research Hypotheses}

\subsection{Theoretical Background}

\subsubsection{Social Cognitive Theory}

Social cognitive theory was first proposed by Bandura, an American psychologist [12], and has become one of the important theories in the fields of pedagogy and social psychology. The core of social cognitive theory is the theory of ternary interaction, that is, the interaction among individual cognition, environment, and behavior. It challenges the traditional view that individual behavior is determined only by internal factors or the external environment. A person's behavior will be affected not only by their own cognition, but also by changes in the external environment. Of course, when individual behavior changes, it will also affect the person's own cognition [12]. Moreover, social cognition theory, which has been verified by many previous studies, explains individual behavior variables well [13]. In this paper, the electronic health literacy of college students is regarded as the internal individual's self-awareness, and the quality of Internet platform is regarded as the external environment variable that affects college students' OMHISB. The influence mechanism model of college students' mental health is constructed from the internal and external perspectives. 


\subsubsection{Information Systems Success Model}

The success model of information systems was proposed by Delone and McLean in 2003 on the basis of their research ten years earlier [8]; it is considered an important point of departure for evaluating the quality of information systems/platforms [14]. Furthermore, Delone and McLean divided it into three dimensions: information quality, system quality, and service quality [8,15]. Information quality is the key variable used to measure semantic success, which reflects the degree of information integrity, accuracy, and real-time output in the form of reports or online screens during the use of the system/platform [16]. System quality is the key variable used to measure technical success, reflecting the reliability and efficiency of the system/platform in processing its own software and data [17]. Service quality is also a key variable by which to measure semantic success $[18,19]$, reflecting the credibility, timeliness, personalization, and specialization of system/platform service quality [17]. Moreover, many previous studies have verified the validity of the model, showing that these three dimensions are one of the key factors in determining the success of an information system/platform [15], and will also have a certain impact on individual behavior. This paper uses the three-dimensional division of Delone and McLean (i.e., information quality, system quality, and service quality) to measure the quality of Internet platforms currently used by college students, and then conducts in-depth research to explore its effect on college students' OMHISB.

Before conducting OMHISB, many college students may form the expected quality of online medical platform [20] through other's word-of-mouth on online medical platforms, or their previous online medical search behavior experience for non-mental health problems. As a result, it will produce students' intuitive experiences of the system, information, and service quality of the online medical platform. Then, when they face some mental health problems, they will consider whether to conduct a mental health consultation online. Therefore, this paper draws on previous studies and incorporates expected quality into the model for further analysis [21].

\subsubsection{Online Mental Health Information Seeking Behavior}

Health information seeking behavior is a concept derived from information seeking, which is defined by Niederdeppe as the behavior that aims to obtain health information in response to specific related events [22]. However, with the development of electronic health care, the Internet has become an important way for people to obtain health information. Some scholars are gradually turning their attention to in-depth research on OMHISB. Among them, Yanxia and Xinxin summarized previous research and defined the concept of OMHISB as the behavioral process in which individuals, guided by their own health information needs, use Internet tools to search, browse, evaluate, select, and use health-related knowledge or information to meet those needs [23]. Subsequently, OMHISB has been studied by more in-depth and developed research, which is of great significance to the current social background of booming Internet use. College students use the Internet more frequently than any other group [4]. How to effectively use college students' OMHISB to promote the development of their mental health has important research value.

\subsubsection{Mental Health}

The study of mental health appeared early, but the initial connotation of mental health focused more on the negative aspects of individuals [24] (i.e., the stage of negative mental health [25]). However, with the continuous development of positive psychology theory, many scholars have found that focusing only on negative aspects makes the study of individual mental health one-sided, and thus the positive aspects of mental health have gradually become the focus of scholarly research [26]. The dual factor model of mental health is established and supported effectively [15] and consists of two dimensions: positive mental health and negative mental health. Negative mental health refers to the elimination of individual mental illness, whereas positive mental health refers to individual happiness and a positive mental state [27]. Based on the dual factor model of mental health, the topic 
of college students' mental health explored in this paper includes both the elimination of individual mental illness and the degree of happiness they perceive.

\subsection{Research Hypotheses}

\subsubsection{Internet Platform Quality and Online Mental Health Information Seeking Behavior}

The success model of an information system indicates that information quality, system quality, and the service quality of the system/platform can on the one hand affect user satisfaction, and on the other hand affect users' intention and behavior [8]. However, when looking at research on the success model of information systems, previous researchers focused on the application of a certain information system or specific platform, and then judged whether the construction of this information system or platform was successful [15]. With the development of Internet technology, Internet platforms gradually began to be integrated into all aspects of life, and in the process of using them, people's perceptions of platform quality can effectively affect their behavior and willingness to use [28,29]. Saeed and others studied users of online retailers, and pointed out that the information quality, system quality, and service quality of online retail platforms have a significant effect on online consumer behavior [30]; similarly, Ho et al. researched online searching behavior of users and found that the quality of websites-information quality, system quality, and service quality — can affect user online information searching [31]. In addition, as a group, college students use the Internet more frequently than the general population [4]; their perception of Internet platform quality also has an impact on their OMHISB. Based on the above research, the following assumptions are put forward on the external perspective:

Hypothesis 1 (H1). The information quality of Internet platforms has a significantly positive impact on the online mental health information seeking behavior of college students.

Hypothesis 2 (H2). The system quality of Internet platforms has a significantly positive impact on the online mental health information seeking behavior of college students.

Hypothesis 3 (H3). The service quality of Internet platforms has a significantly positive impact on the online mental health information seeking behavior of college students.

\subsubsection{Electronic Health Literacy and Online Mental Health Information Seeking Behavior}

Health literacy is an important variable of individual health perception, first proposed by S.K. Simonds in 1974. Health literacy refers to people's ability to acquire and understand health information and use this information to improve their health [32]. However, the development of Internet technology has gradually allowed the Internet to become one of the most important resources for individuals to obtain health information [6]. Canadian scholars, Norman and Skinner, put forward the concept of electronic health literacy for the first time with consideration of the characteristics of contemporary society to refer to the multidimensional abilities to obtain medical health information from electronic resources and use the obtained health information to solve one's own health problems [7]. Subsequently, many scholars have carried out in-depth research on this concept and found that electronic health literacy has an important impact on individual OMHISB. Previous studies have shown that individuals with low levels of health literacy tend to use fewer online portals to search for health information [33]; Britt and Hatten conducted research on college students and found that individuals with high levels of electronic health literacy are more likely to search for health information on the Internet [34]. Jensen found in his research that individuals with low health literacy use less Internet technology to improve their health [35]. Hanik and Stellefson also conducted research on college students and discovered that improving their electronic health literacy has an important impact on their OMHISB [36]. Based on the above, the following assumption is proposed with respect to the internal perspective of individuals: 
Hypothesis 4 (H4). College students' electronic health literacy has a significantly positive impact on their online mental health information seeking behavior.

\subsubsection{Online Mental Health Information Seeking Behavior, Electronic Health Literacy, and Mental Health}

The continuous development of the Internet and mobile technology has changed traditional ways of obtaining and understanding health information [10]. From the internal point of view, when individuals search more health information through the Internet, they can effectively understand their own health status, and reduce anxiety, suspicion, and other negative emotions, thereby improving their mental health [37]. Similarly, when people's levels of electronic health literacy are higher, they are more sensitive to health information and pay more attention to their own health status, thereby improving their mental health. Aref Adib et al. found that patients' OMHISB can effectively improve their mental health status; they also discussed the acceptability of mobile mental health applications [10]. Based on the above, the following assumptions are proposed:

Hypothesis 5 (H5). Electronic health literacy has a significantly positive effect on college students' mental health.

Hypothesis 6 (H6). Online mental health information seeking behavior has a significantly positive effect on college students' mental health.

\subsubsection{The Mediating Role of Online Mental Health Information Seeking Behavior}

Previous studies on the mediating effects of OMHISB are inadequate. Most focused on the previous variables, namely the influencing factors of OMHISB. Externally, the individual's perception of the quality of Internet platforms rarely directly affects their mental health, but the search of Internet health information is the key to connecting the two variables. McKinley and Wright pointed out in their research that individuals' perceptions of information support can trigger OMHISB, leading to a healthier lifestyle [38]. This shows that individuals' perceptions of the external environment can effectively influence physical and mental health with the mediating role of individuals' behaviors in promoting their health. Internally, on the one hand, college students' levels of electronic health literacy will directly affect their mental health; on the other hand, it will further affect the mental health through OMHISB. Dunne et al. found that health promoting behaviors play a mediating role between self-sympathy and physical health [39]. Based on the above, the following assumptions are proposed:

Hypothesis 7a (H7a). Online mental health information seeking behavior plays a mediating role between information quality and college students' mental health.

Hypothesis $\mathbf{7 b} \mathbf{( H 7 b ) . ~ O n l i n e ~ m e n t a l ~ h e a l t h ~ i n f o r m a t i o n ~ s e e k i n g ~ b e h a v i o r ~ p l a y s ~ a ~ m e d i a t i n g ~ r o l e ~ b e t w e e n ~}$ system quality and college students' mental health.

Hypothesis 7c (H7c). Online mental health information seeking behavior plays a mediating role between service quality and college students' mental health.

Hypothesis $\mathbf{7 d}(\mathbf{H 7 d})$. Online mental health information seeking behavior plays a mediating role between electronic health literacy and college students' mental health.

Based on the above research hypotheses and the social cognitive theory and the success model of information system, this paper brings the qualities of the Internet platform-information quality, system quality, and service quality - into the model from the external side, and electronic health literacy into the model from the internal side. Through the mediating role of OMHISB, the influence mechanism model of college students' mental health is constructed, as shown in Figure 1. 


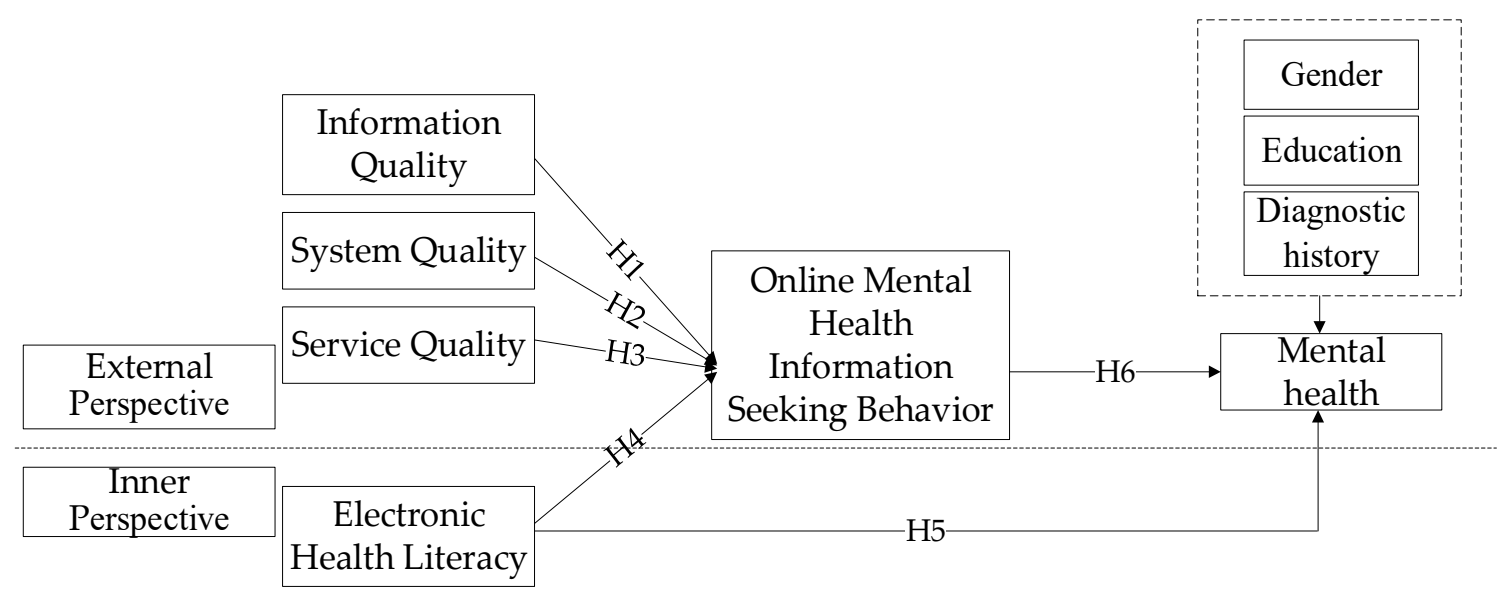

Figure 1. Research model.

\section{Research Methodology}

\subsection{Measurement}

The main potential variables of this research model are information quality (IQ), system quality (SYQ), service quality (SEQ), electronic health literacy (EHL), online mental health information seeking behavior (OMHISB), and mental health (MH). The measurement indexes of seven potential variables are shown in Table 1. The questionnaire is in the form of a Likert 7-point scale. From 1 to 7 , the numbers represent the degree of the respondents' agreement with the question; 1 represents complete disagreement, and 7 represents complete agreement.

Table 1. Variables and indicators used in the research.

\begin{tabular}{|c|c|c|}
\hline Latent Variable & Measurement Item & Reference \\
\hline \multirow{3}{*}{ Information quality (IQ) } & $\begin{array}{l}\text { IQ1: The health information in the Internet medical } \\
\text { platform is updated in time. }\end{array}$ & \multirow{3}{*}{$\begin{array}{l}\text { McKinley and Wright, 2014; } \\
\text { Dunne et al., } 2018[38,39]\end{array}$} \\
\hline & $\begin{array}{l}\text { IQ2: The health information in the Internet medical } \\
\text { platform is accurate. }\end{array}$ & \\
\hline & $\begin{array}{l}\text { IQ3: The health information in the Internet medical } \\
\text { platform is comprehensive. }\end{array}$ & \\
\hline \multirow{5}{*}{ System quality (SYQ) } & SYQ1: The Internet medical platform is reliable. & \multirow{5}{*}{$\begin{array}{l}\text { Shaw and Gant, 2004; } \\
\text { Wixom et al. }[9,40]\end{array}$} \\
\hline & $\begin{array}{l}\text { SYQ2: The Internet medical platform is efficient in } \\
\text { searching health information. }\end{array}$ & \\
\hline & $\begin{array}{l}\text { SYQ3: The Internet medical platform navigation is } \\
\text { effective. }\end{array}$ & \\
\hline & $\begin{array}{l}\text { SYQ4: The layout of the Internet medical platform } \\
\text { is clear. }\end{array}$ & \\
\hline & $\begin{array}{c}\text { SYQ5 The operation of the Internet medical } \\
\text { platform is safe. }\end{array}$ & \\
\hline
\end{tabular}


Table 1. Cont.

\begin{tabular}{|c|c|c|}
\hline Latent Variable & Measurement Item & Reference \\
\hline \multirow{3}{*}{ Service quality (SEQ) } & $\begin{array}{c}\text { SEQ1: The Internet medical platform provides } \\
\text { reliable services. }\end{array}$ & \multirow{3}{*}{$\begin{array}{l}\text { Zha et al., 2014; } \\
\text { Wixom et al. [18,40] }\end{array}$} \\
\hline & $\begin{array}{l}\text { SEQ2: The Internet medical platform provides } \\
\text { timely services. }\end{array}$ & \\
\hline & $\begin{array}{l}\text { SEQ3: The Internet medical platform provides } \\
\text { personalized services. }\end{array}$ & \\
\hline \multirow{4}{*}{ Electronic health literacy (EHL) } & $\begin{array}{l}\text { EHL1: I know where to find useful health resources } \\
\text { on the Internet. }\end{array}$ & \multirow{4}{*}{$\begin{array}{l}\text { Norman and Skinner, 2006; } \\
\text { Shuaijun et al., } 2013[7,41]\end{array}$} \\
\hline & $\begin{array}{l}\text { EHL2: I know how to find useful health resources } \\
\text { on the Internet. }\end{array}$ & \\
\hline & $\begin{array}{l}\text { EHL3: I know how to use the obtained Internet } \\
\text { health information to help myself. }\end{array}$ & \\
\hline & $\begin{array}{l}\text { EHL4: I can distinguish between high-quality and } \\
\text { low-quality Internet health resources. }\end{array}$ & \\
\hline \multirow{3}{*}{$\begin{array}{l}\text { Online mental health } \\
\text { information seeking } \\
\text { behavior (OMHISB) }\end{array}$} & $\begin{array}{l}\text { OMHISB1: I often look for health information on } \\
\text { the Internet medical platform. }\end{array}$ & \multirow{3}{*}{$\begin{array}{l}\text { Zha et al., 2014; Yan and } \\
\text { Davison, } 2013[18,42]\end{array}$} \\
\hline & $\begin{array}{l}\text { OMHISB2: I frequently seek health information on } \\
\text { the Internet medical platform. }\end{array}$ & \\
\hline & $\begin{array}{l}\text { OMHISB3: I spend a lot of time looking for health } \\
\text { information on the Internet medical platform. }\end{array}$ & \\
\hline \multirow{5}{*}{ Mental health (MH) } & MH1: I am still interested in the past. & \multirow{5}{*}{$\begin{array}{l}\text { Zigmond and Snaith, 2007; } \\
\text { Nunnally, } 1978[43,44]\end{array}$} \\
\hline & MH2: I can laugh and see the good side of things. & \\
\hline & MH3: I feel happy. & \\
\hline & MH4: I am optimistic about everything. & \\
\hline & MH5: I can adjust my mood quickly. & \\
\hline
\end{tabular}

The qualities of Internet platforms—information quality, system quality, and service quality—are based on the research of Wixom and Todd, Zha, and others [18,40], and are modified according to the actual situation. Finally, the questionnaire required in this paper was formed with a total of 11 measurement items. There are three items of information quality, five items of system quality, and three items of service quality. For example, "I think the health information in the Internet medical platform is updated in time"; "I think the Internet medical platform is reliable"; and "I think the Internet medical platform provides reliable services".

Electronic health literacy is mainly based on the scale compiled by Norman and Skinner [7], and is modified according to the actual situation. There are four measurement items in total. For example, "I know where to find useful health resources on the Internet."

Online mental health information seeking behavior, based on the research questionnaire compiled by Zha et al. and Yan and Davison, has three measurement items [18,42]. For example, "I often look for health information on the Internet medical platform."

Mental health is based on the hospital anxiety and depression scale compiled by Zigmond and Snaith $[43,44]$. In this paper, combined with the group characteristics of college students and the actual investigation, we make appropriate modifications to a total of five measurement items. For example, "I feel happy" and "I look forward optimistically to everything."

\subsection{Respondents and Data Collection}

To verify the rationality and validity of the theoretical model proposed in this paper, this study uses a questionnaire survey method to collect firsthand data for empirical analysis. By 2020, there were more than 2600 institutions of higher learning and more than 40 million college students in China. In this study, by means of Internet and telephone interviews, we conducted a questionnaire survey on the OMHISB of some college students in Internet health information platforms. 
This study uses the method of random questionnaire to investigate college students in China. First of all, to verify the validity of the questionnaire, we first conducted field research and distributed the questionnaire in a university in Anhui Province. A total of 50 copies was distributed in the early stage for pre-investigation in a college in Anhui, and items were modified based on the results. Subsequently, the questionnaire was revised and distributed in colleges and universities nationwide. In addition, in the questionnaire survey, in order to ensure that the subjects conducted an online search for mental health issues, in the questionnaire, we clearly pointed out that the attention of the subjects is an investigation of the online search behavior and effect of mental health problems, and through the reverse question to ensure that the subject was of online mental health search behavior. In the later questionnaire sorting, questionnaires without OMHISB were eliminated. In this survey, a total of 550 questionnaires was issued. After eliminating the invalid questionnaires, 491 valid questionnaires were collected, for a total effective rate of $89.27 \%$. The specific sample data statistics are shown in Table 2.

Table 2. Sample statistics.

\begin{tabular}{cccc}
\hline College Students & Type & Number & Proportion \\
\hline \multirow{2}{*}{ Gender } & Male & 235 & $47.86 \%$ \\
& Female & 256 & $52.14 \%$ \\
\hline \multirow{3}{*}{ Age } & Under 18 years old & 30 & $6.11 \%$ \\
& 18-20 years old & 212 & $43.18 \%$ \\
& 20-24 years old & 196 & $39.92 \%$ \\
& Over 24 years old & 53 & $10.79 \%$ \\
\hline \multirow{2}{*}{ Education } & Junior college & 94 & $19.14 \%$ \\
& Undergraduate & 257 & $52.34 \%$ \\
& Master & 88 & $17.92 \%$ \\
& Doctor and above & 52 & $10.59 \%$ \\
\hline
\end{tabular}

\section{Results}

\subsection{Measurement Model Evaluation}

The partial least squares method or maximum likelihood method were used to analyze the structural model. The partial least squares method is widely used in exploratory factor analysis because of its relatively loose requirements for normal distribution of sample data quality and its flexibility in dealing with missing data. In addition, there was no significant difference between the two methods in the analysis of large sample data. Therefore, this paper mainly used SPSS20 (IBM, Armonk, NY, USA) and SmartPLS3.0(SmartPLS GmbH, Bönningstedt, Germany) for analysis, and partial least squares regression structural equation model (SEM) to verify the measurement model and structural model.

\subsubsection{Descriptive Statistical Analysis}

First, a descriptive statistical analysis of sample data was carried out, and the analysis results are shown in Table 3. According to the analysis results, the mean value of each variable item of the model ranged from 4.326 to 4.89 , and the standard deviation range was from 1.484 to 1.738 , which shows that the data are relatively centralized, the fluctuation is small, and the model has good adaptability. In addition, the factor load of each item ranged from 0.834 to 0.912 , which is higher than the threshold value of 0.7 . This shows that the measurement index of each latent variable has high correlation and convergence validity [45], indicating that the items set in the questionnaire are reasonable. 
Table 3. Descriptive statistical results of data.

\begin{tabular}{ccccc}
\hline Latent Variable & Variable Item & Mean Value & Standard Deviation & Factor Load \\
\hline \multirow{2}{*}{ Information quality (IQ) } & IQ1 & 4.766 & 1.617 & 0.874 \\
& IQ2 & 4.89 & 1.623 & 0.885 \\
& IQ3 & 4.868 & 1.738 & 0.898 \\
\hline \multirow{2}{*}{ System quality (SYQ) } & SYQ1 & 4.511 & 1.518 & 0.859 \\
& SYQ2 & 4.517 & 1.672 & 0.882 \\
& SYQ3 & 4.53 & 1.634 & 0.867 \\
& SYQ4 & 4.426 & 1.532 & 0.859 \\
& SYQ5 & 4.464 & 1.565 & 0.844 \\
\hline \multirow{2}{*}{ Service quality (SEQ) } & SEQ1 & 4.544 & 1.561 & 0.9 \\
& SEQ2 & 4.462 & 1.651 & 0.9 \\
\hline \multirow{2}{*}{ Electronic health literacy (EHL) } & SEQ3 & 4.642 & 1.648 & 0.875 \\
& EHL1 & 4.572 & 1.655 & 0.873 \\
& EHL2 & 4.326 & 1.609 & 0.869 \\
\hline Online mental health & EHL3 & 4.354 & 1.511 & 0.871 \\
\hline information seeking & EHL4 & 4.546 & 1.533 & 0.878 \\
behavior (OMHISB) & OMHISB1 & 4.493 & 1.573 & 0.889 \\
\hline & OMHISB2 & 4.546 & 1.586 & 0.889 \\
\hline
\end{tabular}

\subsubsection{Common Method Bias Assessment}

Considering the questionnaire survey, the data was collected from one single source, which may lead to common method bias. This paper adopted program control methods, including two methods of process control and statistical control, to ensure that the questionnaire did not produce serious common method bias problems. Process control was mainly used for anonymous filling of the survey to reduce the ambiguity of the questionnaire and improve the clarity of the questionnaire, as far as possible to avoid errors caused by factors such as inaccurate concept measurement and mutual interference between responders. In addition, this paper also adopted a statistical control method, that is, Harman's single factor test was performed on the recovered data, and the principal component analysis method was used to perform factor analysis on the total variance of the interpretation of the measured indicators. The results show that the total measurement index has a total of six principal components (eigenvalues $>1$ ), and the variance of the first principal component factor is $30.01 \%$, which is lower than the threshold of $40 \%$, showing that a single principal component does not have very strong explanatory power. It can be seen that the sample data survey results of this paper do not have serious common method bias problems, and the explanatory power of all measurement index items is within an acceptable range.

\subsubsection{Reliability and Validity Test}

The measurement quality of the questionnaire can be analyzed for its reliability and validity. The test results are shown in Table 4. 
Table 4. Reliability and validity test.

\begin{tabular}{cccccccccc}
\hline Variables & Alpha & CR & AVE & IQ & MH & SEQ & EHL & SYQ & OMHISB \\
\hline Information quality & 0.863 & 0.916 & 0.784 & 0.886 & & & & & \\
Mental health & 0.903 & 0.928 & 0.721 & 0.503 & 0.849 & & & & \\
Service quality & 0.888 & 0.93 & 0.817 & 0.462 & 0.719 & 0.904 & & & \\
Electronic health literacy & 0.895 & 0.927 & 0.761 & 0.562 & 0.724 & 0.659 & 0.872 & & \\
$\quad$ System quality & 0.914 & 0.935 & 0.744 & 0.493 & 0.714 & 0.66 & 0.706 & 0.862 & \\
Online mental health & 0.863 & 0.916 & 0.785 & 0.532 & 0.73 & 0.676 & 0.654 & 0.676 & 0.886 \\
information seeking behavior & & & & & & & & & \\
\hline
\end{tabular}

Abbreviations: $\mathrm{CR}=$ composite reliability; $\mathrm{AVE}$ = average variance extraction.

From the reliability test of the questionnaire, Cronbach's $\alpha$ value is usually used for observation. Cronbach's $\alpha$ value reflects the reliability of the measurement indicators of the potential variables in the questionnaire. The higher the value, the higher the reliability of the scale. In this model, Cronbach's $\alpha$ of all measurement variables is greater than the recommended value of 0.7 [45], and its range is from 0.863 to 0.917 , which shows that the reliability of the questionnaire is good.

Based on the test, the validity of the questionnaire can be divided into aggregation validity and differentiation validity. First, let us adapt the perspective of aggregation validity. Aggregation validity is a test to measure the consistency of multiple measurement items under the same construct. Hair et al. pointed out that factor load, composite reliability (CR), and average variance extraction (AVE) are three effective indicators to test the polymerization validity [46]. The factor load of the model is shown in Table 3, and the factor load of each observation variable exceeds the recommended value of 0.6 , indicating that the observation variable of the model has a high correlation with the structural variable [47]. The CR value describes the degree to which observation variables determine the potential structure, and also reflects the degree of internal consistency of variables. The $C R$ value of the model ranges from 0.916 to 0.938 , which is 0.7 higher than the recommended value, indicating that the internal consistency of the model variables is good, and the observation variables set can better explain the potential model structure. The AVE value reflects the total difference of indicators occupied by potential structure. The AVE in this model ranges from 0.721 to 0.817 , beyond the recommended value of 0.5 [46]. It shows that the observation variables in this model explain each measurement dimension well [48].

Discriminative validity refers to the degree of uncorrelation between the measurement indexes of each latent variable and the measurement indexes of other latent variables [49]. The discrimination validity can be measured by the square root of each AVE observation variable. In this model, the square root of each AVE observation variable is greater than the correlation coefficient between each AVE observation variable and other observation variables, indicating that each observation variable has a strong discrimination coefficient and a high degree of discrimination.

According to the above analysis, the questionnaire design of this study is reasonable and has good reliability and validity. The design of the measurement model is effective and reasonable, which can be used for further structural model fitting analysis.

\subsection{Structural Model Analysis}

\subsubsection{Total Effect Analysis}

The structural model points out the causal relationship among the variables in the model [50]. In this study, the theoretical model proposed by SmartPLS3.0 software is used for structural equation analysis, and the analysis results are shown in Figure 2. 


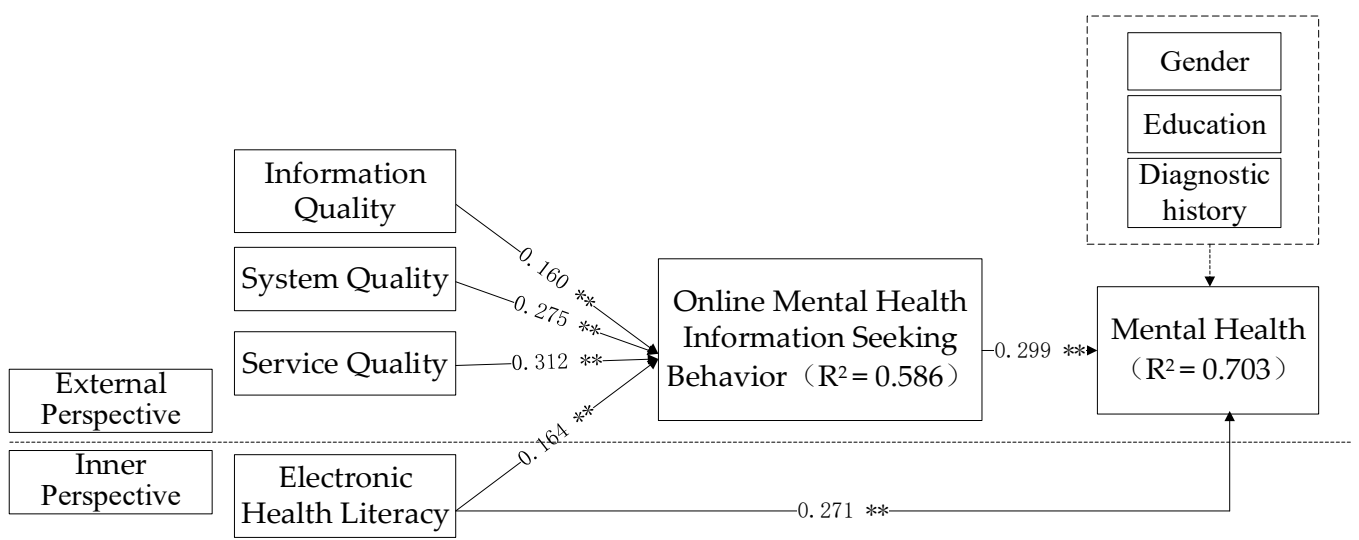

Figure 2. Model fitting diagram. Note: ${ }^{* *}$ means $p<0.01$.

From the analysis results of the above model, we can draw the following conclusions: First, it analyzes the influence of internal and external factors on college students' OMHISB. Among the factors, the information quality of external Internet platform $(\beta=0.160, p<0.01)$, system quality $(\beta=$ $0.275, p<0.01)$, and service quality $(\beta=0.312, p<0.01)$ have significantly positive effects on college students' OMHISB; the internal perspective of individual electronic health literacy $(\beta=0.164, p<0.01)$ also has significantly positive effects on college students' OMHISB, and the common explanation variance is $58.6 \%$. Moreover, from the above analysis results, it can be seen that for college students, the effect of external factors is greater than that of internal factors, in that the impact of Internet platform quality on college students' OMHISB is greater than their own awareness and initiative for health. It is assumed that $\mathrm{H} 1, \mathrm{H} 2, \mathrm{H} 3$, and $\mathrm{H} 4$ are all verified.

Secondly, it analyzes the direct effect of improving the mental health of college students. From the above analysis results, we can see that the individual's electronic health literacy $(\beta=0.271, p<0.01)$ and OMHISB $(\beta=0.299, p<0.01)$ have a significantly positive impact on the improvement of college students' mental health, with a total explanatory variance of $70.3 \%$, justifying the variables to a large degree. Among them, OMHISB has the greatest impact on their mental health, followed by electronic health literacy. It is assumed that $\mathrm{H} 5$ and $\mathrm{H} 6$ are all verified. The mediating role of OMHISB still needs further analysis.

Thirdly, it analyzes the effect of mental health of college students after adding control variables. $t$-Test results show that gender, education level and, whether there is clear historical mental disease diagnosis have no significant difference on college students' mental health. This means that attribute variables have no significant effect on empirical analysis results.

\subsubsection{Mediating Effect Analysis}

To test the mediating effect of OMHISB, this study established two models and used SmartPLS3.0 software for structural model analysis. Model 1 includes only variables such as Internet platform quality, electronic health literacy, and mental health, and analyzes the impact of direct effects. The analysis results are shown in Figure 3. Model 2 adds mediating variables, namely OMHISB, to test its mediating role on the basis of Model 1. The analysis results are shown in Figure 4. 


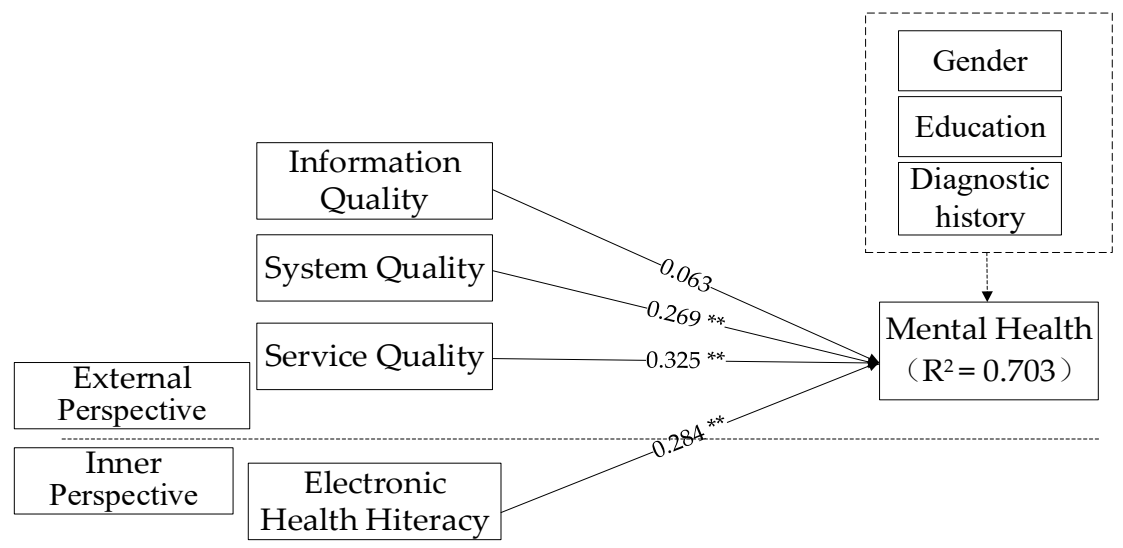

Figure 3. Fitting diagram of direct effect model (Model 1). Note: ${ }^{* *}$ means $p<0.01$.

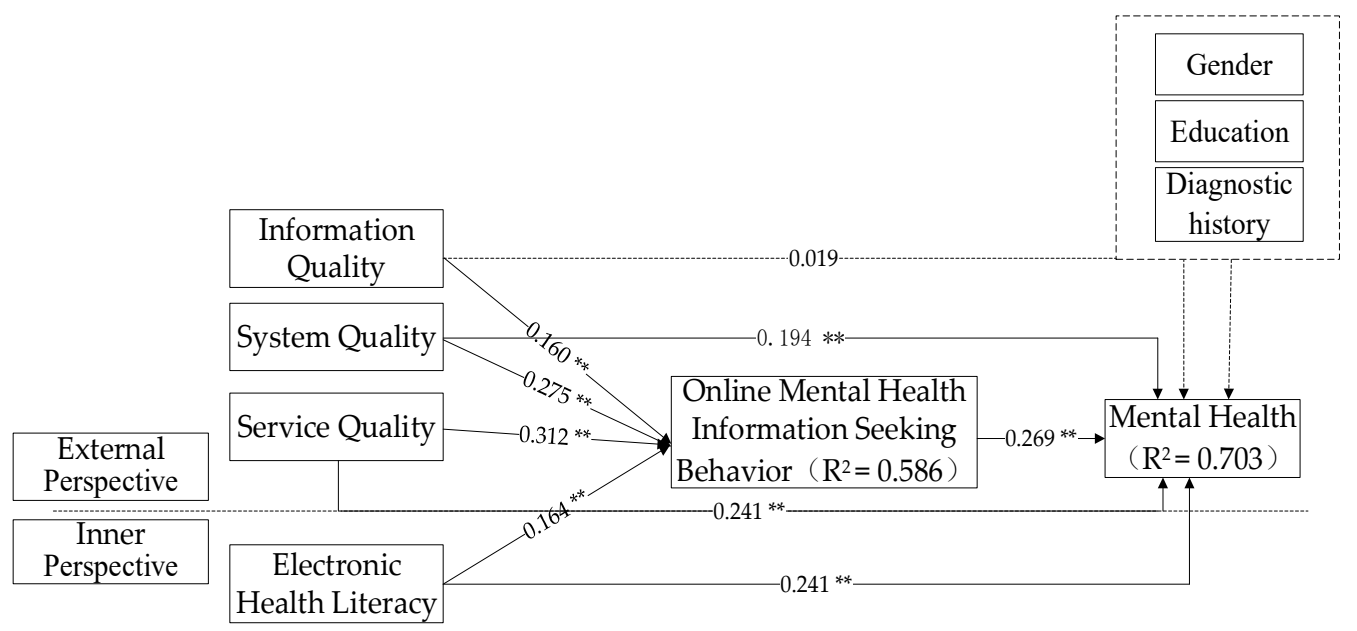

Figure 4. Analysis diagram of mediating effect (Model 2). Note: ${ }^{* *}$ means $p<0.01$.

In Model 1, the quality of Internet platform and electronic health literacy has some significant effects on the improvement of college students' mental health. Among them, the system quality $(\beta=0.269, p<0.01)$, service quality $(\beta=0.325, p<0.01)$, and individual electronic health literacy $(\beta=0.284, p<0.01)$ have a significantly positive impact on the improvement of college students' mental health, and the mediating effect of OMHISB can be considered [51]. However, information quality $(\beta=0.063, p>0.01)$ has no significant effect on the improvement of mental health, so it is impossible to consider the mediating role of OMHISB, assuming H8a is not tenable.

In Model 2, compared with Model 1, the regression coefficient between the system quality of Internet platforms and the mental health of college students decreased from $\beta=0.269$ to $\beta=0.194$ and the $t$-value decreased from 5.723 to 4.011 after the addition of the OMHISB variable. This shows that OMHISB plays a mediating role between the system quality and the mental health of college students. H8b is verified. Similarly, OMHISB plays a mediating role in service quality, electronic health literacy, and the mental health of college students, assuming that H8c and H8d are verified. Therefore, Internet health information seeking plays a mediating role between the quality of an Internet platform and electronic health literacy, and the mental health of college students, assuming that $\mathrm{H} 7$ is partially established. The final hypothesis test results are shown in Table 5. 
Table 5. The estimation results of structural parameters.

\begin{tabular}{cccc}
\hline Hypothetical Path & Path Coefficient & T Statistics & Conclusion \\
\hline H1: Information Quality $\rightarrow$ OMHISB & $0.16^{* *}$ & 4.237 & Support \\
H2: System Quality $\rightarrow$ OMHISB & $0.275^{* *}$ & 5.763 & Support \\
H3: Service Quality $\rightarrow$ OMHISB & $0.312^{* *}$ & 7.368 & Support \\
H4: Electronic Health Literacy $\rightarrow$ OMHISB & $0.164^{* *}$ & 3.573 & Support \\
H5: Electronic Health Literacy $\rightarrow$ Mental Health & $0.271^{* *}$ & 8.003 & Support \\
H6: OMHISB $\rightarrow$ Mental Health & $0.299^{* *}$ & 8.547 & Support \\
H7: Mediating Role of OMHISB & - & - & Partial support \\
Gender $\rightarrow$ Mental Health & 0.011 & 0.765 & No support \\
Education $\rightarrow$ Mental Health & 0.034 & 0.891 & No support \\
Diagnostic History $\rightarrow$ Mental Health & 0.029 & 0.237 & No support \\
\hline
\end{tabular}

Note: ${ }^{* *}$ means $p<0.01$.

\section{Discussion}

\subsection{Implications for Research}

Based on the internal and external perspectives, this paper explores the influence mechanism of college students' mental health through the mediating role of OMHISB, which mainly has the following theoretical contributions:

First, through empirical research methods, this paper puts forward the influence mechanism model of college students' mental health and proves it. Previous scholars have studied more directly the existing mature mental health scale and directly through the scale score to analyze their mental health status. The research on the impact mechanism of their mental health is insufficient and needs to be improved [15]. In addition, there are a wide range of studies on the impact mechanism of college students' mental health [51,52]. However, few scholars analyze the impact mechanism of college students' mental health from the perspective of college students' information technology and Internet application. Considering that college students are a community that frequently uses the Internet [4], the Internet also has an important impact on their mental health. This paper explores the influence mechanism of college students' mental health in terms of internal electronic health literacy and external Internet platform quality, enriches the theoretical basis of the influence mechanism of college students' mental health, and provides the theoretical basis for follow-up research.

Second, in this paper, OMHISB as a variable is included in the theoretical model to analyze the impact of its mediating effect. Previous studies on the mediating effect test of OMHISB are inadequate, while more research focuses on its previous variables, namely the influencing factors of OMHISB [15]. This paper includes OMHISB in the model and verifies the mediating effect of internal and external factors on college students' mental health, which enriches the theoretical basis of OMHISB. In addition, this study finds that the mediating effect of OMHISB between information quality and the mental health of college students cannot be established, which is different from previous research [53]. Considering the differences of research targets, since health information is professional information in general, it is difficult to accurately judge the quality of health information for ordinary nonmedical college students [54]. Therefore, there is no significant mediating correlation between information quality and mental health in Internet health information searching behavior. It suggests that we should pay attention to the differences of research situations in studying the factors and behavioral results of Internet behavior.

Third, in this paper, we built a model of the impact mechanism of college students' mental health from both external and internal perspectives. The external perspective combines with the development of information technology to consider the quality of the network platform, and the internal perspective combines the individual's acceptance of information technology to consider the internal electronic health literacy of college students, which lead to a more comprehensive analysis of the impact mechanism of college students' mental health. The previous research is more from a single 
perspective [38], or to compare the impact mechanism of college students' mental health in different research background [55]. This study analyzes in-depth on the basis of the previous one, which also enriches the theoretical basis of college students' mental health and provides an important theoretical basis for subsequent research.

\subsection{Implications for Practice}

College students' mental health has always been the focus of social concern, and certain cultural or social changes have made maintaining mental health more challenging. Their mental health problems may lead to bad behaviors that affect their ability to study and their quality of life, such as alcohol, irritability, and even suicide. This paper studies and analyzes the mental health of college students from the perspective of Internet use, which is of great practical significance in terms of alleviating their mental health problems to a certain extent.

Firstly, from the individual point of view, using the Internet to search for relevant health information and giving full play to the advantages of the Internet can help college students effectively understand their health status and reduce anxiety, suspicion, and other negative emotions [38] so as to improve their mental health. This has important practical significance.

Secondly, from the perspective of platform managers, improving the quality of the health care platform, including information quality, system quality, and service quality, is of great value. Improving the quality of the platform by optimizing its design and strengthening data management will help promote college students' searching for health information on the Internet, and it has an important role in improving their mental health.

Thirdly, colleges and universities have an incentive to improve students' electronic health literacy, an essential component of institutions of higher education, because it can effectively improve their mental health.

\subsection{Limitations and Future Research Directions}

Based on the internal and external perspectives, this paper explores the influence mechanism of college students' mental health through the mediating role of OMHISB. This has certain theoretical value and practical significance, but there are also some shortcomings. First, this paper is about college students in China, which has certain geographical limitations and research object limitations. Second, Internet platforms mentioned in this paper generally refer to online medical platforms used by various college students. The quality of different platforms is uneven, yet this paper does not distinguish between them. This needs to be further improved in the future.

\section{Conclusions}

This study constructs a theoretical model that influences college students' OMHISB from internal and external perspectives and by extension affects their mental health. Through field research and questionnaires, a structural equation model is used to test the hypotheses. The main results are as follows.

Firstly, the quality of external Internet platforms and the quality of internal electronic health literacy have a significantly positive impact on the online health information searching behavior of college students. The results show that the three dimensions of Internet platform quality-information quality, system quality, and service quality—can effectively promote college students' OMHISB, and can improve college students' consciousness of actively searching for health information on Internet platforms $[29,30]$. Moreover, students' perception of platform service quality has the greatest impact on their online health searching, whereas the platform's information quality and the internal perspective of electronic health literacy have relatively little impact. This shows that with changes over time, contemporary college students' perception of the quality of information while searching the Internet for health information is no longer the main focus of attention; rather, the quality of service occupies an important position. More attention is paid to the services received in the process of searching for 
information, which is a breakthrough compared with previous research [31,32]. The possible reason is that health information is generally professional knowledge. Nonmedical college students have difficulty accurately judging the quality of health information [55], so the sensitivity to service quality will be greater than the sensitivity to information quality.

Secondly, electronic health literacy and OMHISB have significantly positive effects on college students' mental health. The results show that when college students choose to use OMHISB, they will have more opportunities to connect with knowledge about mental health, and they will also have easier access to the required information about mental health. In turn, timely assessment and adjustment of their own mental health status, through the reduction of anxiety, suspicion, and other negative emotions will thereby improve their mental health [38]. Similarly, when their level of electronic health literacy is high, they will pay more attention to their own mental health status, again improving their mental health.

Thirdly, online health information searching behavior is established in the mediating role of Internet platform quality, electronic health literacy, and college students' mental health. The results show that Internet health information searching plays a mediating role in the system quality, service quality, electronic health literacy, and mental health of college students. After adding OMHISB variables, the original direct effect is significantly reduced. However, its mediating role between information quality and mental health is not established, and college students' perception of information quality on Internet platforms will not directly promote their mental health; therefore the mediating role cannot be considered [51]. This may be related to the influence of the change in contemporary college students' values, and more attention should be paid to the quality of service in information searches. At the same time, it may also be caused by the high degree of professionalism of health information, which makes it difficult for college students to form an effective perception of its quality [55].

Author Contributions: C.L. conceived the research; W.C. established the research model and wrote the draft; Q.Z. and Y.X. collected the data and conducted data analysis; D.G. provided some guiding suggestions and revised the paper. All authors read and approved the final manuscript.

Funding: This research was partially supported in the collection, analysis, and interpretation of data by the National Natural Science Foundation of China under Grant Nos. 71771075 and 71771077; the Research Project of Innovative Development of Social Science in Anhui Province in China No. 2018CX045; the Anhui Soft Science Project in China No. 201806a02020052; and Fundamental Research Funds for the Central Universities with No. PA2020GDKC0020.

Conflicts of Interest: The authors declare no conflicts of interest.

\section{References}

1. Yuan, M.Y. Confusions about and solutions for leisure sports development in China. J. Phys. Educ. 2013, 20, 33-37.

2. Roseberry-Mckibbin, C.; Pieretti, R.; Haberstock, K.; Estrada, J. Effective pedagogical strategies for millennial university students in communicaiton sciences and disorders: Student survey results. Commun. Disord. Q. 2015, 37, 180-183. [CrossRef]

3. Burt, K.B.; Paysnick, A.A. Identity, stress, and behavioral and emotional problems in undergraduates: Evidence for interaction effects. J. Coll. Stud. Dev. 2014, 55, 368-384. [CrossRef]

4. Kim, Y.; Sohn, D.; Choi, S.M. Cultural difference in motivations for using social network sites: A comparative study of American and Korean college students. Comput. Hum. Behav. 2011, 27, 365-372. [CrossRef]

5. Yu, B.; Hu, X. Toward training and assessing reproducible data analysis in data science education. Data Intell. 2019, 1, 333-344. [CrossRef]

6. Hsu, P.F.; Ray, S.; Li-Hsieh, Y.Y. Examining cloud computing adoption intention, pricing mechanism, and deployment model. Int. J. Inf. Manag. 2014, 34, 474-488. [CrossRef]

7. Norman, C.D.; Skinner, H.A. eHealth literacy: Essential skills for consumer health in a networked world. J. Med. Int. Res. 2006, 8, e9. [CrossRef]

8. Delone, W.H.; Mclean, E.R. The DeLone and McLean Model of Information Systems Success: A Ten-Year Update. J. Manag. Inf. Syst. 2003, 19, 9-30. 
9. Shaw, L.H.; Gant, L.M. In defense of the Internet: The relationship between Internet communication and depression, loneliness, self-esteem, and perceived social support. J. Obstet. Gynaecol. Can. 2004, 5, 41. [CrossRef]

10. Aref-Adib, G.; O’Hanlon, P.; Fullarton, K.; Morant, N.; Sommerlad, A.; Johnson, S.; Osborn, D. A qualitative study of online mental health information seeking behaviour by those with psychosis. BMC Psychiatry 2016, 16, 232. [CrossRef]

11. Peris, R.; Gimeno, M.A.; Pinazo, D.; Ortet, G.; Carrero, V.; Sanchiz, M.; Ibanez, I. Online chat rooms: Virtual spaces of interaction for socially oriented people. CyberPsychol. Behav. 2002, 5, 43-51. [CrossRef] [PubMed]

12. Grusec, J.E. Social learning theory and developmental psychology: The legacies of Robert Searsand Albert Bandura. Dev. Psychol. 1992, 28, 776-786. [CrossRef]

13. Dzewaltowski, D.A.; Noble, J.M.; Shaw, J.M. Physical activity participation: Social cognitive theory versus the theories of reasoned action and planned behavior. J. Sport Exerc. Psychol. 1990, 12, 388-405. [CrossRef]

14. Cody-Allen, E.; Kishore, R. An Extension of the UTAUT Model with E-Quality, Trust, and Satisfaction Constructs. In Proceedings of the 2006 ACM SIGMIS CPR Conference on Computer Personnel Research: Forty Four Years of Computer Personnel Research: Achievements, Challenges \& the Future, Claremont, CA, USA, 13-15 April 2006; pp. 82-89.

15. Delone, W.H.; Mclean, E.R. Measuring e-commerce success: Applying the DeLone \& McLean information systems success model. Int. J. Electron. Commer. 2004, 9, 31-47.

16. Zhou, T. Examining the critical success factors of mobile website adoption. Online Inf. Rev. 2011, 35, 636-652. [CrossRef]

17. Gorla, N.; Somers, T.M.; Wong, B. Organizational impact of system quality, information quality, and service quality. J. Strateg. Inf. Syst. 2010, 19, 207-228. [CrossRef]

18. Zha, X.; Zhang, J.; Yan, Y.; Xiao, Z. User perceptions of e-quality of and affinity with virtual communities: The effect of individual differences. Comput. Hum. Behav. 2014, 38, 185-195. [CrossRef]

19. Zha, X.; Zhang, J.; Yan, Y.; Xiao, Z. Does affinity matter? Slow effects of e-quality on information seeking in virtual communities. Libr. Inf. Sci. Res. 2015, 37, 68-76. [CrossRef]

20. Lange, C.; Issanchou, S.; Combris, P. Expected versus experienced quality: Trade-off with price. Food Qual. Prefer. 2000, 11, 289-297. [CrossRef]

21. Rust, R.T.; Inman, J.J.; Jia, J.; Zahorik, A. What You Don't Know about Customer-Perceived Quality: The Role of Customer Expectation Distributions. Mark. Sci. 1999, 18, 77-92. [CrossRef]

22. Anker, A.E.; Reinhart, A.M.; Feeley, T.H. Health information seeking: A review of measures and methods. Patient Educ. Couns. 2011, 82, 346-354. [CrossRef] [PubMed]

23. Yanxia, S.; Xinxin, L. A Summary of Research on Public Internet Health Information Search Behavior. Mod Intell. 2018, 38, 157-163.

24. Suldo, S.M.; Huebner, E.S. Is extremely high life satisfaction during adolescence advantageous? Soc. Indic. Res. 2006, 78, 179-203. [CrossRef]

25. Merrell, K.W. Linking prevention science and social and emotional learning: The Oregon Resiliency Project. Psychol. Sch. 2010, 47, 55-70. [CrossRef]

26. Seligman, M.; Csikszentmihalyi, M. Positive psychology: An introduction. Am. Psychol. Assoc. 2000, 55, 5. [CrossRef]

27. Greenspoon, P.J.; Saklofske, D.H. Toward an integration of subjective well-being and psychopathology. Soc. Indic. Res. 2001, 54, 81-108. [CrossRef]

28. Jeong, M.; Lambert, C.U. Adaptation of an information quality framework to measure customers' behavioral intentions to use lodging Web sites. Int. J. Hosp. Manag. 2001, 20, 129-146. [CrossRef]

29. Hsu, F.-M.; Chen, T.-Y. Understanding information systems usage behavior in E-Government: The role of context and perceived value. In Proceedings of the Pacific Asia Conference on Information Systems, PACIS 2007, Auckland, New Zealand, 4-6 July 2007.

30. Saeed, K.A.; Hwang, Y.; Mun, Y.Y. Toward an integrative framework for online consumer behavior research: A meta-analysis approach. J. Organ. End User Comput. (JOEUC) 2003, 15, 1-26. [CrossRef]

31. Ho, L.-A.; Kuo, T.-H.; Lin, B. The mediating effect of website quality on Internet searching behavior. Comput. Hum. Behav. 2012, 28, 840-848. [CrossRef]

32. Simonds, S.K. Health education as social policy. Health Educ. Monogr. 1974, 2, 1-10. [CrossRef]

33. Sarkar, U.; Karter, A.J.; Liu, J.Y.; Adler, N.E.; Nguyen, R.; Lopez, A.; Schillinger, D. The literacy divide: Health literacy and the use of an internet-based patient portal in an integrated health system-Results from the Diabetes Study of Northern California (DISTANCE). J. Health Commun. 2010, 15, 183-196. [CrossRef] [PubMed] 
34. Britt, R.K.; Hatten, K.N. Need for cognition and electronic health literacy and subsequent information seeking behaviors among university undergraduate students. Sage Open 2013, 3, 2158244013508957. [CrossRef]

35. Jensen, J.D.; King, A.J.; Davis, L.A.; Guntzviller, L.M. Utilization of internet technology by low-income adults: The role of health literacy, health numeracy, and computer assistance. J. Aging Health 2010, 22, 804-826. [CrossRef] [PubMed]

36. Hanik, B.; Stellefson, M. E-Health Literacy Competencies among Undergraduate Health Education Students: A Preliminary Study. Int. Electron. J. Health Educ. 2011, 14, 46-58.

37. Jiang, S.; Street, R.L. Pathway linking Internet health information seeking to better health: A moderated mediation study. Health Commun. 2017, 32, 1024-1031. [CrossRef]

38. McKinley, C.J.; Wright, P.J. Informational social support and online health information seeking: Examining the association between factors contributing to healthy eating behavior. Comput. Hum. Behav. 2014, 37, 107-116. [CrossRef]

39. Dunne, S.; Sheffield, D.; Chilcot, J. Brief report: Self-compassion, physical health and the mediating role of health-promoting behaviours. J. Health Psychol. 2018, 23, 993-999. [CrossRef]

40. Wixom, B.H.; Todd, P.A.A. theoretical integration of user satisfaction and technology acceptance. Inf. Syst. Res. 2005, 16, 85-102. [CrossRef]

41. Shuaijun, G.; Xiaoming, Y.; Yuying, S. The Chineseization and Applicability of eHEALS Health Literacy Scale. Chin. Health Educ. 2013, 29, 106-108.

42. Yan, Y.; Davison, R.M. Exploring Behavioral Transfer from Knowledge Seeking to Knowledge Contributing: The Mediating Role of Intrinsic Motivation. J. Assoc. Inf. Sci. Technol. 2013, 64, 1144-1157. [CrossRef]

43. Zigmond, A.S.; Snaith, R.P. The Hospital Anxiety and Depression Scale. Acta Psychiatr. Scand. 2007, 67, 361-370. [CrossRef] [PubMed]

44. Nunnally, J. Psychometric Theory, 2nd ed.; McGraw-Hill: New York, NY, USA, 1978.

45. Hair, J.F. Multivariate data analysis: A global perspective; Pearson Education.: Upper Saddle River, NJ, USA, 2010.

46. Chin, W.W.; Gopal, A.; Salisbury, W.D. Advancing the Theory of Adaptive Structuration: The Development of a Scale to Measure Faithfulness of Appropriation. Inf. Syst. Res. 1997, 8, 342-367. [CrossRef]

47. Fornell, C.; Larcker, D.F. Erratum: Structural Equation Models with Unobservable Variables and Measurement Error: Algebra and Statistics. J. Mark. Res. 1981, 18, 427. [CrossRef]

48. Cheung, C.M.K.; Lee, M.K.O. A theoretical model of intentional social action in online social networks. Decis. Support. Syst. 2010, 49, 24-30. [CrossRef]

49. Sang, S.; Lee, J.D.; Lee, J. E-government adoption in Cambodia: A partial least squares approach. Transform. Gov. People Process Policy 2010, 4, 138-157. [CrossRef]

50. Zhang, N.; Zhou, Z.M.; Su, C.T.; Zhou, N. How Do Different Types of Community Commitment Influence Brand Commitment? The Mediation of Brand Attachment. Cyberpsychol. Behav. Soc. Netw. 2013, 16, 836-842. [CrossRef]

51. Sonnak, C.; Towell, T. The impostor phenomenon in British university students: Relationships between self-esteem, mental health, parental rearing style and socioeconomic status. Pers. Individ. Differ. 2001, 31, 863-874. [CrossRef]

52. El Ansari, W.; Adetunji, H.; Oskrochi, R. Food and mental health: Relationship between food and perceived stress and depressive symptoms among university students in the United Kingdom. Cent. Eur. J. Public Health 2014, 22, 90-97. [CrossRef]

53. Leung, L. Internet Embeddedness: Links with Online Health Information Seeking, Expectancy Value/Quality of Health Information Websites, and Internet Usage Patterns. CyberPsychol. Behav. 2008, 11, 565-569. [CrossRef]

54. Fang, G.; Guangming, M.; Xuehai, Z. Investigation and Analysis of Medical and Non-Medical College Students' Awareness of AIDS. China AIDS STD 2004, 3, 200-201+205.

55. Niu, Z.; Willoughby, J.F.; Mei, J.; Li, S.; Hu, P.A. Cross-Cultural Comparison of an Extended Planned Risk Information Seeking Model on Mental Health Among College Students: Cross-Sectional Study. J. Med. Internet Res. 2020, 22, 15817. [CrossRef] [PubMed]

(C) 2020 by the authors. Licensee MDPI, Basel, Switzerland. This article is an open access article distributed under the terms and conditions of the Creative Commons Attribution (CC BY) license (http://creativecommons.org/licenses/by/4.0/). 